\title{
Dispersion of brine discharge from seawater reverse osmosis desalination plants
}

\author{
Yolanda Fernández-Torquemada*, José Miguel Gónzalez-Correa, Angel Loya, \\ Luis Miguel Ferrero, Marta Díaz-Valdés, José Luis Sánchez-Lizaso \\ Department of Marine Sciences and Applied Biology, University of Alicante, PO Box 99, E-03080 Alicante, Spain \\ Tel. +34 96590 3400, ext. 2916; Fax +34 96590 9840; email: Yolanda.Fernandez@ua.es
}

Received 30 September 2008; Accepted 16 March 2009

\begin{abstract}
A B S T R A C T
Desalination of seawater has been considered as a potential solution for the water shortage problem in coastal areas and the number of projected and constructed desalination plants has significantly increased in recent years. The challenge of the desalination industry is to produce new water resources without increasing the pressure on the marine environment. Environmental impact of SWRO desalination plants is mainly associated with the discharge into the sea of the brine produced. To estimate the area of influence of the brine several models have been proposed, but validation with real data is needed. The objective of this paper is to present the results of the monitoring of the brine effluent emanating from several SWRO desalination plants in the western Mediterranean Sea in order to estimate the area of influence of the hypersaline plume. We also illustrate how the behavior of these brine discharges can differ significantly according to discharge characteristics. This information may be useful to predict effluent distribution in order to minimize the harmful effects of brine discharges into the sea.
\end{abstract}

Keywords: Desalination discharge; Monitoring; Plume dispersion; Brine dilution

\section{Introduction}

During the last few decades existing freshwater sources have become increasingly limited in many regions of the world [1,2], particularly in countries along the Arabian Gulf, the Mediterranean coast and the Red Sea, due to the elevated consumption and low precipitation occurring in these zones [3,4]. Desalination is a maturing technology that has been widely utilised for freshwater supply throughout the world for many years [2,5]. Therefore, seawater desalination has been considered as a

${ }^{*}$ Corresponding author. feasible alternative available to satisfy the demand of water, and the number of projected and constructed desalination plants has increased throughout this region in recent years [4].

Although there are several desalination technologies, such as those based on thermal processes (e.g. multi-stage flash, multi-effect distillation and vapour compression) or the ones based on membrane processes (e.g. electrodialysis, reverse osmosis, nanofiltration), currently the reverse osmosis $(\mathrm{RO})$ method is the preferred desalination technique in these new facilities, mainly due to its low energy and space consumption and the reduction in the cost of the potable water obtained [2,6-8]. RO consists of applying external pressure to a concentrated solution, like 
seawater, in order to force the flow of water molecules through a semi-permeable membrane, producing a permeate which consists of fresh water and rejected brine [9]. Therefore, this brine is fundamentally water, relatively concentrated in dissolved salts (44-90 psu) by a factor related to the water recovery rate (product water/ feedwater, $\approx 30-70 \%$ ) utilized during the desalination process [10]. Additionally, some chemicals (such as biocides, anti-scalants, coagulants, antifoaming agents, etc.) used in the desalination processes, and toxic metals (if the discharge water has been in contact with metallic materials) may accompany the brine $[6,7,11,12]$.

There are different options for the concentrate disposal from a desalination plant such as its discharge into the sea, into deep wells or into evaporation ponds, its treatment on wastewater plants or the production of salt and other minerals [13-17]. But cost plays an important role in the selection of the disposal method and today ocean brine disposal is considered the least expensive one $[7,12,15,16]$.

If the concentrate is discharged directly into the sea, it will form a plume of elevated density that will descend to the sea floor and extend horizontally following the slope of the sea bottom bathymetry [18]. This hypersaline mass of water could negatively affect several benthic marine organisms around the discharge point that usually live in stable salinity environments $[8,12,19,20]$. The most sensitive communities will be the most affected, perhaps resulting in total disappearance of these species inside the area of brine influence.

To date, available information regarding the behavior of these hypersaline effluents and their effect on the marine ecosystem is insufficient $[18,21,22]$. However, the discharge of brine into the sea requires particular attention and scientific assessment of possible impact on the marine environment. The magnitude of these potential impact will depend not only on the characteristics of the desalination plant and its reject brine, but also on the nature of the physical (i.e., bathymetry, hydrodynamics, etc.) and biological conditions of the receiving marine environment $[7,12,15,20]$. A number of models have been proposed to simulate the brine discharge into the sea, the CORMIX being the most widely used of them [23]. However, the models need to be validated with actual data, and field measurements of brine discharge are scarce.

The main objective of this paper is to present the results of the monitoring of the brine effluent originating in several SWRO desalination plants in the western Mediterranean Sea in order to estimate the area of influence of the hypersaline plume. We also illustrate how the behavior of these brine discharges can differ widely according to discharge characteristics. This information may be useful to predict effluent distribution in order to minimize the harmful effects of brine discharges into the sea.

\section{Material and methods}

\subsection{Location and description of the studied desalination plants and their brine discharge}

We carried out the monitoring of the brine discharge from three SWRO desalination plants with different characteristics, located in the SE of Spain, over a period of several years (Fig. 1). The monitoring programs have been adapted to these characteristics and to the local conditions existing in the brine disposal areas.

\subsubsection{Jávea desalination plant}

The Jávea (Alicante, SE Spain, Fig. 1) SWRO desalination plant began operations in June 2002, using seawater obtained from coastal deep wells $(200 \mathrm{~m})$ as feedwater. It has four lines of approximately $7000 \mathrm{~m}^{3} \mathrm{~d}^{-1}$ each. However, this plant has been operating with two lines in summer and one line in autumn, winter and spring. Brine (68 psu) is initially mixed with four times its volume of seawater to obtain a level of salinity lower than $44 \mathrm{psu}$, and it is emitted by 16 horizontal diffusers to increase its dilution into an artificial channel of $700 \mathrm{~m}$ long, $20 \mathrm{~m}$ wide and $1 \mathrm{~m}$ depth (La Fontana Channel) that discharges close to a beach.

\subsubsection{New Channel of Alicante I desalination plant}

The SWRO desalination plant of New Channel of Alicante I began operations in September 2003 at Alicante (SE Spain, Fig. 1). Intake water was obtained from beach wells. Initially, it had a maximum capacity of $50,000 \mathrm{~m}^{3} \mathrm{~d}^{-1}$ with a recovery of $42-44 \%$, which represented a discharge of $66,000 \mathrm{~m}^{3} \mathrm{~d}^{-1}$ with a salinity of $68 \mathrm{psu}$. However, in January 2006 it was enlarged to produce up to $68,000 \mathrm{~m}^{3} \mathrm{~d}^{-1}$ although the production has remained

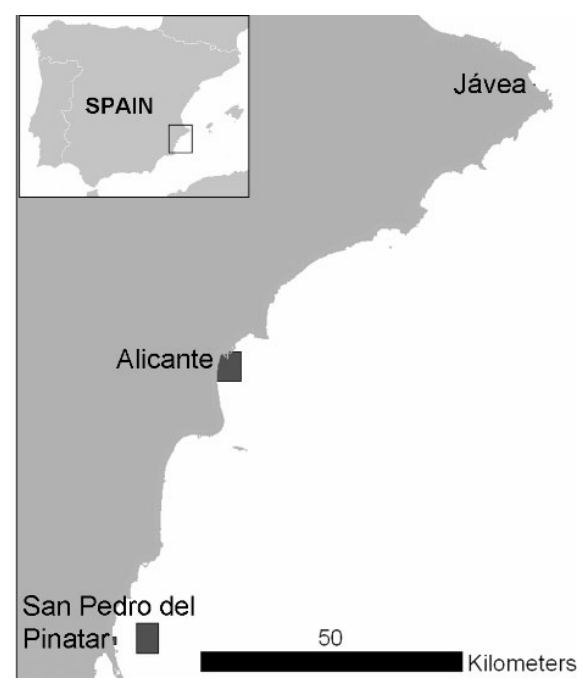

Fig. 1. Location of the desalination plants whose brine discharges were studied in the present work. 
around $60,000 \mathrm{~m}^{3} \mathrm{~d}^{-1}$ most of the time. Following this increase in capacity, the option of diluting the brine with seawater prior to discharge was adopted. The dilution of the brine is not constant and has been oscillating between 1.5 and 5 parts of water to each part of brine according to the results of the monitoring program. The discharge is located directly on the shoreline south of Alicante harbour.

\subsubsection{New Channel of Cartagena desalination plants}

AtSan Pedro del Pinatar (Murcia, SE Spain, Fig. 1), two desalination plants of $68,000 \mathrm{~m}^{3} \mathrm{~d}^{-1}$ each have been constructed. For seawater supply one of the desalination plants utilises a superficial reception of seawater by means of horizontal directed drilled wells while the other has an open intake. The average recovery rate of the plant is approximately $44 \%$, implying rejected water with an elevated salinity $(\approx 70 \mathrm{psu})$. These desalination plants are located in an area of high environmental value, and in order to avoid discharge close to the protected Posidonia meadows, the discharge of both plants is carried out via a 5 -km-long pipeline at $38 \mathrm{~m}$ depth. However, since the first plant was in operation before the pipeline was completed, a provisional discharge facility was implemented at $2 \mathrm{~m}$ depth with variable dilution with seawater. During the provisional discharge period (May 2005-January 2006), the production ranged from one to four lines (7000$\left.28,000 \mathrm{~m}^{3} \mathrm{~d}^{-1}\right)$. From January to November 2006 the discharge was $75,000 \mathrm{~m}^{3} \mathrm{~d}^{-1}$ without bypassing seawater. However, from November 2006 the discharge was doubled due to the operation of the second desalination plant.

\subsection{Monitoring of the effluent dispersion}

\subsubsection{Field campaigns and data acquisition}

In order to estimate the temporal and spatial dispersion of brine in the closest area to the effluent discharge, we carried out several oceanographic surveys throughout the year for the three desalination plants. In each of these campaigns, measurements were taken at several stations located at different distances from their outfalls. The extension of the studied area and the grid spacing between stations depended on the production of the desalination plant, on the type of discharge and on the receiving environment (bathymetry and hydrodynamic regimes). At each station, vertical distribution of salinity was obtained using conductivity, temperature and depth (CTD) devices with a measuring range of 0-70 psu and a resolution $\pm 0.01 \mathrm{psu}$. All the stations were positioned using a GPS (precision $\pm 5 \mathrm{~m}$ ) based on UTM coordinates. The number of stations was established depending on the size of the plume ranging from 30 (Jávea) to 120 (Alicante).

\subsubsection{Spatial data analysis and representation}

An interpolation of the data obtained in each campaign was made using the kriging technique for the purpose of obtaining a real representation of the studied variables in the space. Kriging is used to predict the values of a variable at unsampled locations based on a geostatistical model. In order to validate this model we used a crossvalidation test that compares estimated values with the real measured values. The kriging prediction was subsequently presented in the form of contour maps to obtain the graphical spatial representation of salinity data in the studied area. Both processes, kriging and cross-validation, were performed using the extension Geostatistical Analyst of the ArcGIS(C) v.9.0 software [24].

\section{Results}

\subsection{Jávea desalination plant}

Over the years monitoring the Jávea desalination plant, we have observed that the initial dilution of the concentrate produced a final discharged effluent on the Fontana channel that never reached a salinity level higher than $44 \mathrm{psu}$. Outside the channel, both the form and direction of the brine plume were shown to be related with the bathymetry within the discharge area, although the dispersion of this brine was also associated with the local currents, these being slightly displaced to the north (Figs. 2C and 2D).

Moreover, throughout all the campaigns the extent of the brine plume appeared to diminish (Fig. 2) and levels approaching total dilution were detected in the surface waters. In addition, stratification was observed between the bottom and surface waters, due to the density difference between seawater and brine. The data obtained from the different campaigns, also showed a seasonal and spatial variation of salinity distribution (Fig. 2). During the summer months with two desalination lines operating, most elevated salinities on the seabed were usually confined to the constrained area formed by the Fontana channel and within a distance of about $300 \mathrm{~m}$ surrounding the channel outfall (Figs. 2C and 2D), whereas during the rest of the year the SWRO desalination plant utilized one line and the area influenced by increasing salinity was smaller (Figs. 2A and 2B).

\subsection{Alicante I desalination plant}

Results of the Alicante desalination plant monitoring showed that the surface salinity remained stable over time showing no clear trend in any of the surveys undertaken. However, this contrasts with the salinity increment found on the seafloor for some surveys (Fig. 3). In this figure it 

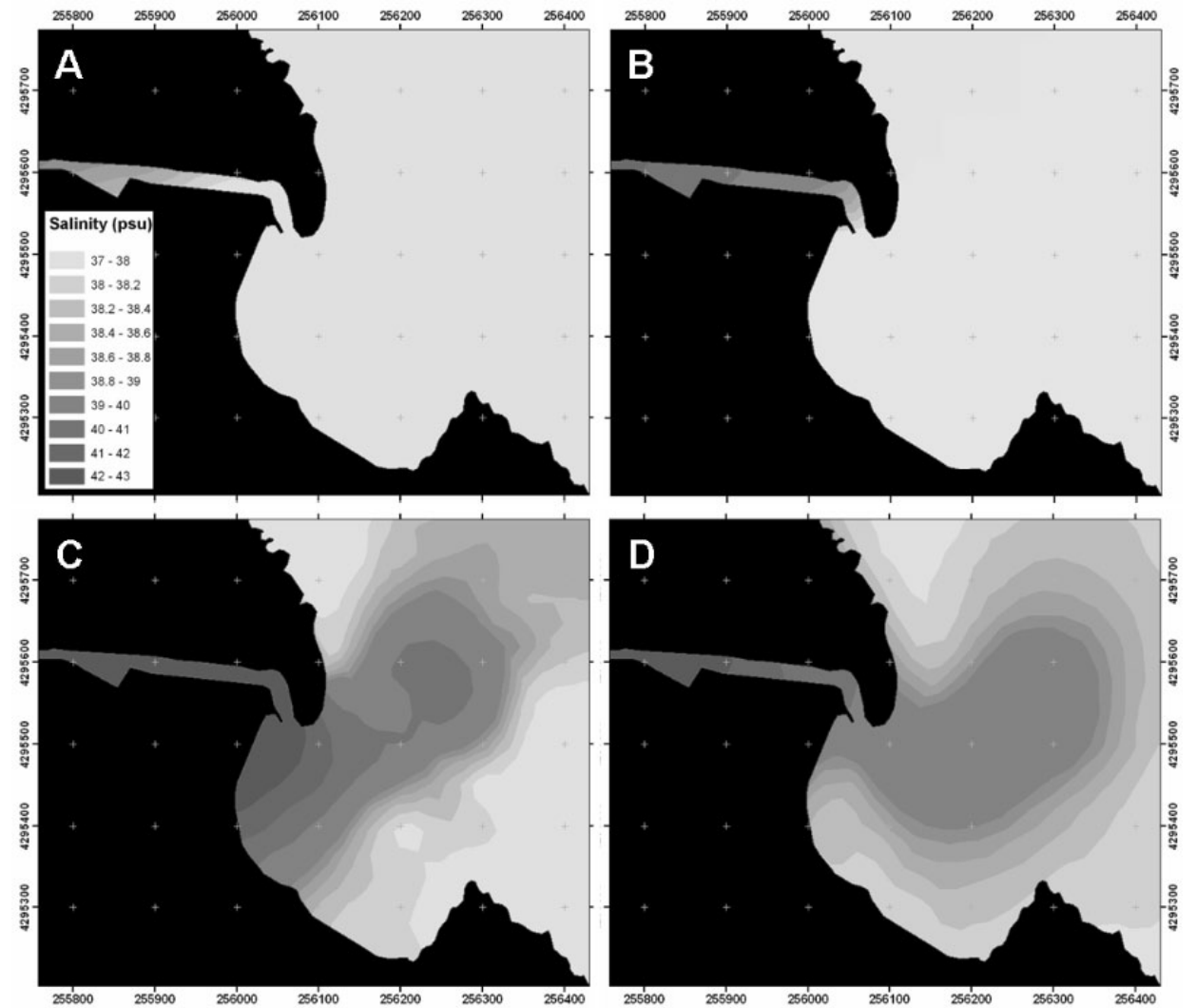

Fig. 2. Bottom salinity representations in the vicinity of the Fontana Channel outfall, obtained in March 2003 (A) , February 2004 (B), August 2006 (C) and July 2007 (D).
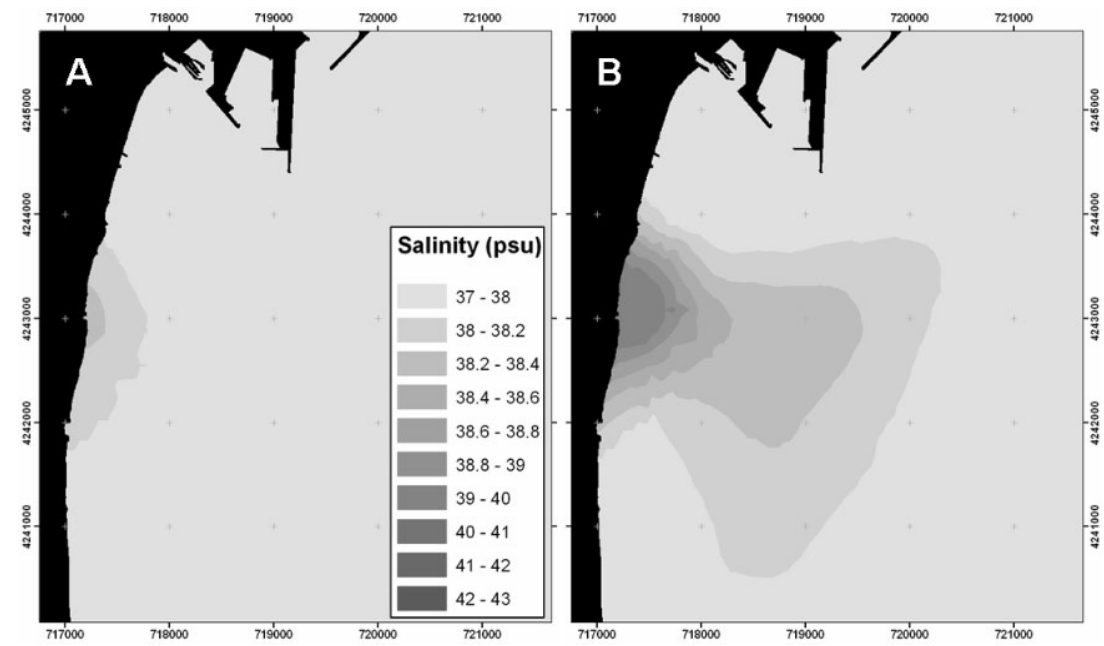

Fig. 3. Spatial distribution of salinity on the surface (A) and on the sea bottom (B) during the campaign of May 2008.

can also be observed that the dilution close to the discharge is very fast but a high level of stability could be found far from the discharge point. Brine dispersal follows the bathymetry and spreads as it moves away from the discharge point.

However, this trend did not prove to be the case throughout the whole year, since during the summer period and due to the formation of a seasonal thermocline, maximum salinity was not found at the sea bottom. Instead, it was found at the thermocline at 12-13 m deep (Fig. 4). This is the consequence of the lower temperatures under the thermocline, which caused the density under the thermocline to be higher that at the brine level. At the sea floor (Fig. 4A) salinity increase is only observed in the 

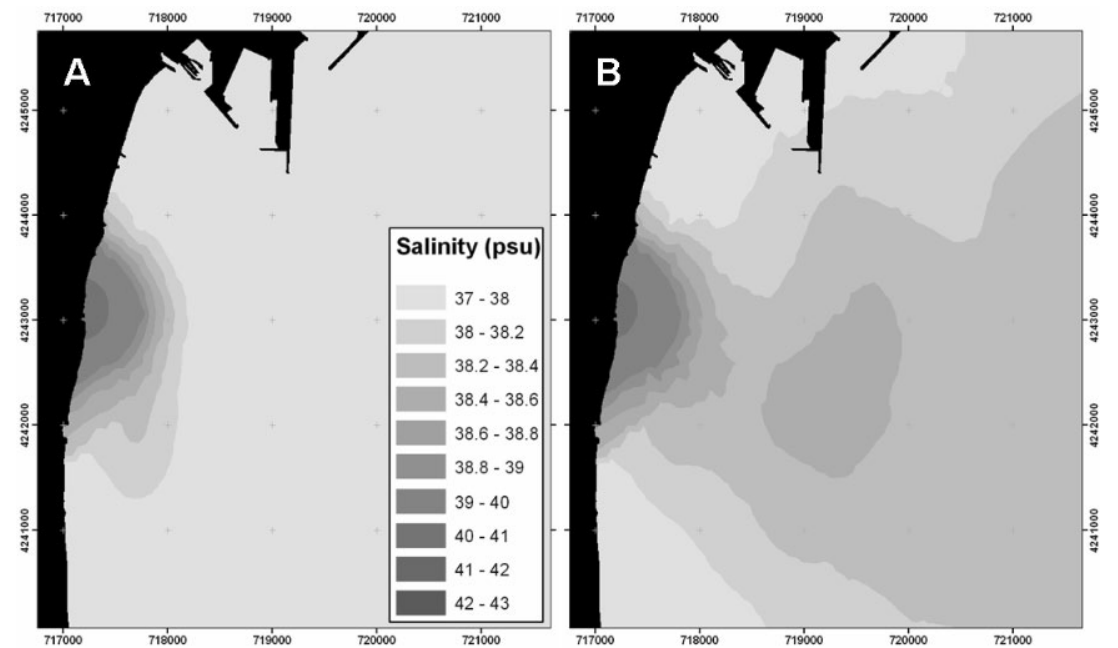

Fig. 4. Spatial representation of salinity distribution on the sea floor (A) and at the thermocline level (B) in June 2007.
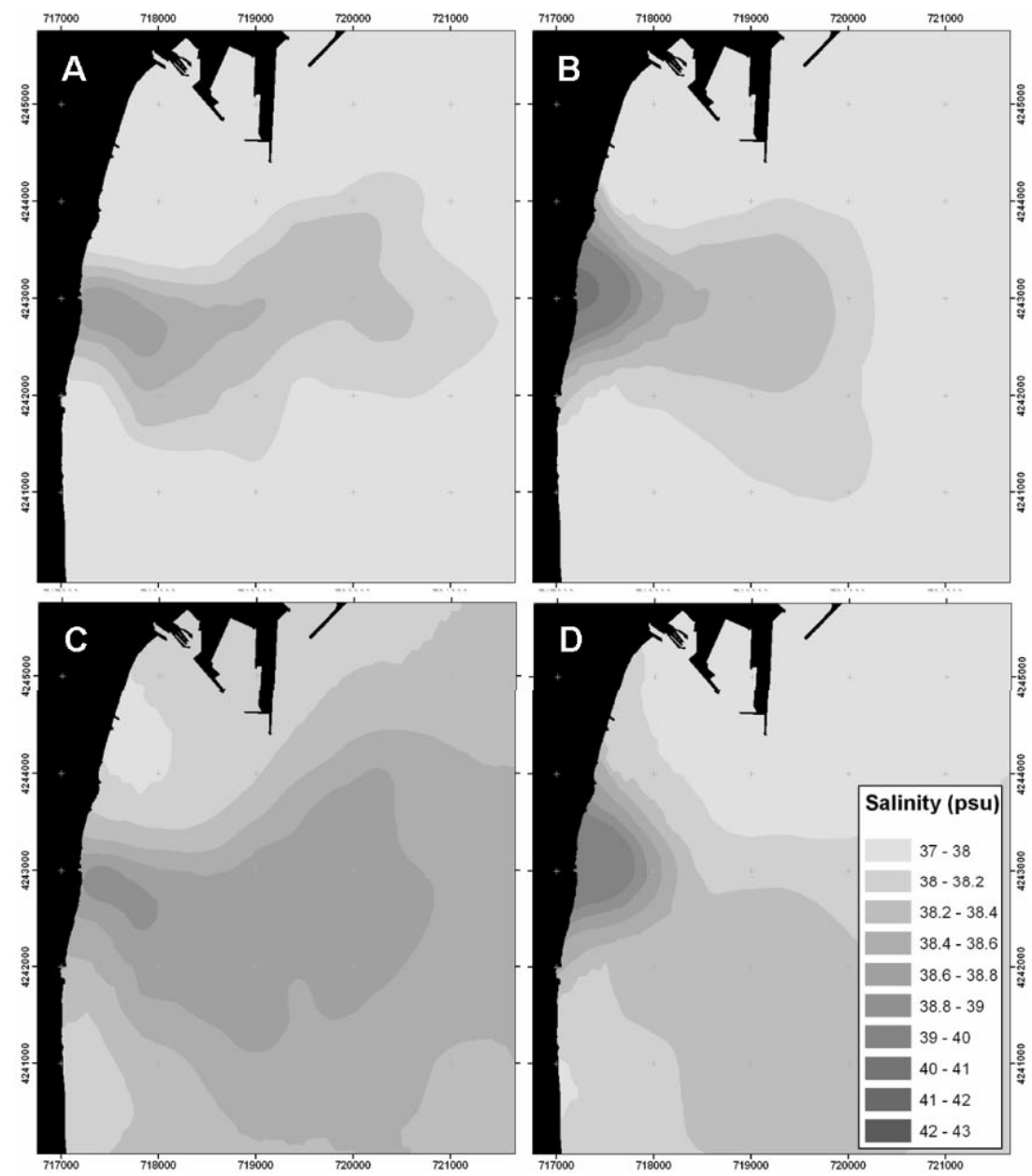

Fig. 5. Brine dispersion representations from January 2005 (A), January 2007 (B), April 2004 (C) and April 2006 (D).

first few hundred meters, a factor which may produce an erroneous assumption that dilution has taken place. At the thermocline level, where maximum salinity is observed, a similar pattern to those in the rest of surveys was also found (Fig. 4B). We also observed that although the quantity of brine discharge increased with the enlargement of the desalination plant in January 2006, the area of influence of the brine was similar or smaller. This was 

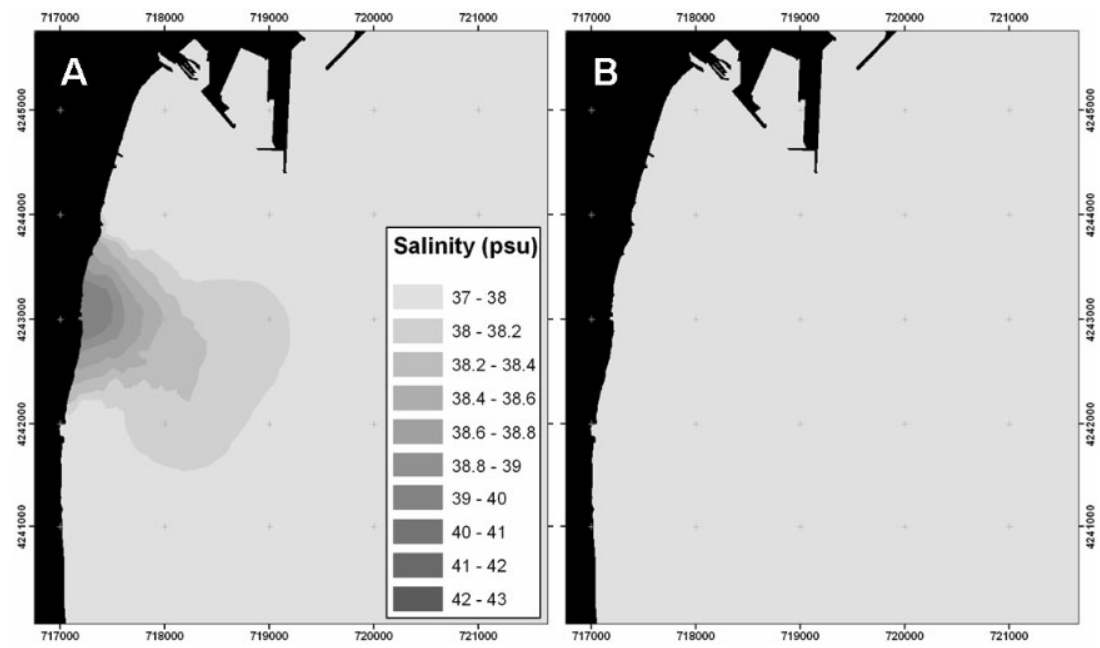

Fig. 6. Spatial distribution of salinity on the sea floor on October 2007 (A) and October 2006 (B).


Fig. 7. Spatial representation of salinity distribution on the sea floor close to the provisional brine discharge point of the San Pedro del Pinatar desalination plant obtained in four different surveys: (A) 8 June, (B) 22 June, (C) 14 July and (D) 18 August.

attributable to the increase of previous dilution with seawater (Figs. 5B and 5D) than when the desalination plant had a lower level of production (Figs. 5A and 5C).
Moreover, in some of these surveys we found that increases of salinity at the bottom were observed several kilometers away from the discharge point. 

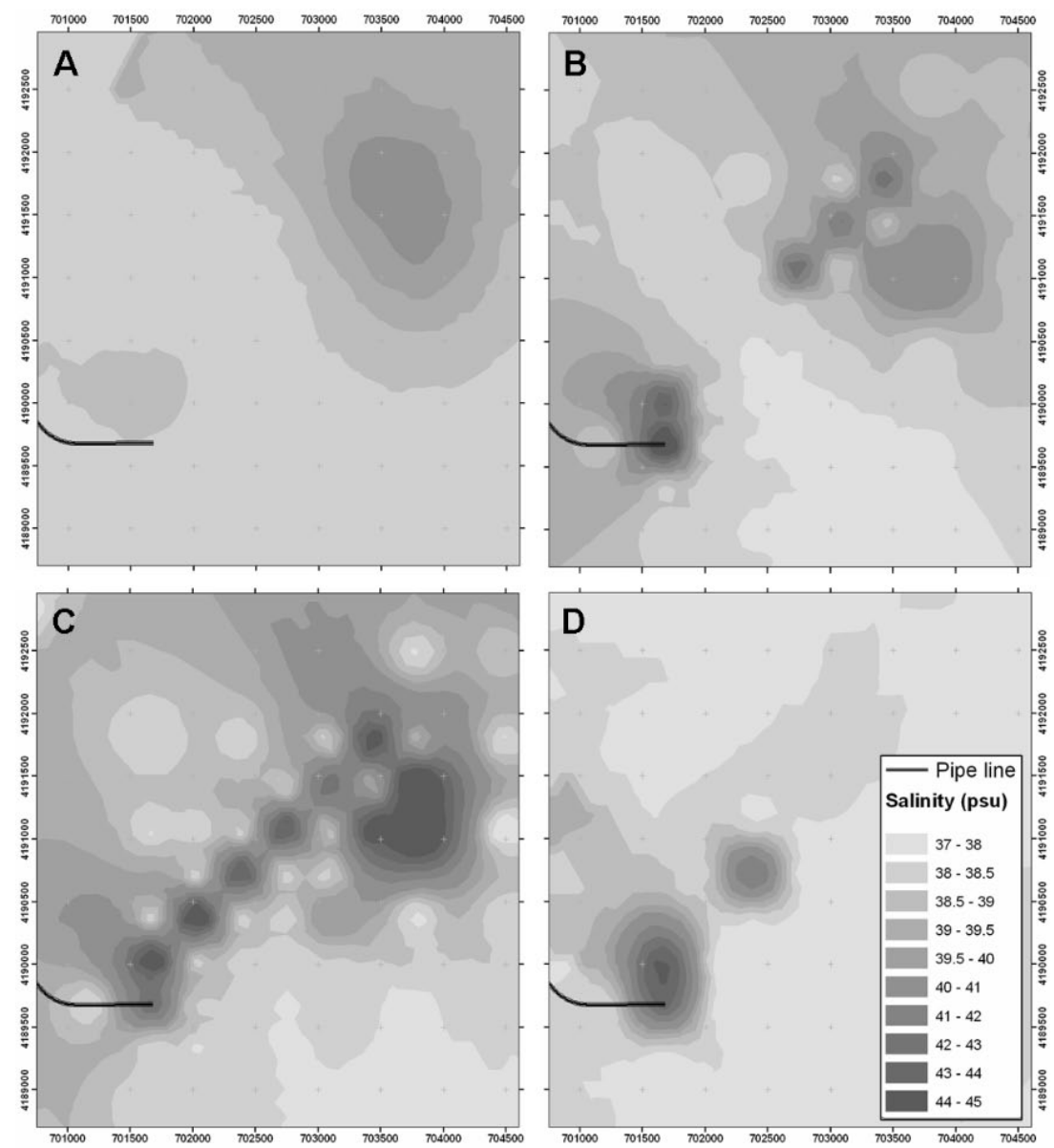

Fig. 8. Spatial distribution of salinity on the sea floor close to the San Pedro del Pinatar pipeline discharge with one desalination plant operating in March (A) and July 2006 (B), and with two desalination plants, in January (C) and July 2007 (D).

On the other hand, we want to highlight that the area of influence of the discharge may be reduced by increasing the dilution with sea water. Fig. 6 represents the surveys carried out in October 2007 (6A) when the desalination plant dilution was one part brine and two parts seawater and October 2006 (6B) with a dilution of one part brine to four parts seawater. As we can see, for the same period of the year, the brine dilution is higher when seawater bypassing was incremented.

\subsection{San Pedro del Pinatar desalination plants}

Fig. 7 shows some examples of the results obtained in the surveys carried out in order to estimate the spatial dispersion of the provisional discharge from San Pedro del Pinatar desalination plant. We detected the highest salinities in the June survey, when the desalination plant was working with three lines and 2.84 dilution. But even in this case, the spatial distribution of the brine plume is markedly reduced (Fig. 7B). In this figure we can also observe that brine dispersion is guided by the direction in which the bathymetry increases as well as by the pre- dominant north to south coastal currents of the area. When later, in July, the desalination plant operated using three lines, the dilution increased to 3.44, while in August (D) even though the production was increased to four lines, the dilution only registered 3.03 .

In January 2006 the construction of the main pipeline for the desalination plant was concluded, and we continued carrying out surveys in the vicinity of this new outfall. Fig. $8 \mathrm{~A}$ and $8 \mathrm{~B}$ represent the brine dispersion of this desalination plant during March and July 2006, respectively, whereas Fig. $8 \mathrm{C}$ and $8 \mathrm{D}$ correspond to January and July 2007 when there were two desalination plants operating and discharging through the same pipeline.

\section{Discussion}

In this paper we have presented the results of the monitoring of the brine effluent originating from several SWRO desalination plants, estimating the area of influence of each hypersaline plume. The expanse of this plume varies significantly, depending on the kind of dis- 
charge and level of production of each desalination plant. For example, we have estimated that the total dilution of the brine discharge from the small desalination plant of Jávea with previous dilution of the brine takes place within a short distance $(<300 \mathrm{~m})$. On the other hand, we have observed that the area of influence of the brine discharge emanating from larger desalination plants, such as the ones at Alicante and San Pedro del Pinatar, is much larger, and as it spreads along the bottom, it reaches a distance of several kilometers from the discharge point.

It has also been found that the extension and behavior of the reject brine plume may vary seasonally. This is true in the case of the Jávea desalination plant where the most elevated salinity values and the highest brine plume distribution were observed at the seabed during summer when the vertical mixing of the water column was reduced and the stratification was facilitated by the greatest frequency of calm conditions. However, in the winter the area influenced by increasing salinity was always smaller. These seasonal differences can be explained by a general reduction in the seawater salinity, a lower level of production of the desalination plant and the freshwater flows observed next to the channel outlet during the winter months, as a consequence of the higher precipitation occurring in the zone at this time of year. Moreover, in the vicinity of the outfall from the Alicante desalination plant we detected the formation of a seasonal thermocline at a depth of 12-15 $\mathrm{m}$ during the summer when, due to the low temperature of water below this thermocline, the brine remained in the middle of the water column and did not affect the benthic organisms that inhabit the sea floor.

In all the desalination plants studied we have observed that prior dilution of the concentrate bypassing seawater to reduce the difference in densities between the brine and the seawater reduced the area of influence of the hypersaline plume. In the Jávea desalination plant a 4:1 dilution ratio was enough to ensure a final salinity discharge of less than 44 psu. In addition, in Alicante and in the provisional coastal discharge from San Pedro del Pinatar we observed that, although the level of brine discharge was increased, the dilution produced a plume extension similar or smaller than when the desalination plants registered a lower production level.

Other methods used for maximizing the brine dilution and consequently reducing the area of influence include the use of diffusers that may increase the velocity of discharge and mixing in the near field. This phenomenon was observed inside the Fontana Channel where the Jávea desalination plant discharges its brine through sixteen diffusers. It must be emphasized that this is an artificial channel which passes through a benthic community of relatively little importance, which makes it an ideal location for the brine discharge. In addition, it has been observed that this concentrated discharge has diminished the problems of anoxia generated by the previous lack of water circulation inside the channel.

In this paper it has been shown how the extent of the hypersaline plume associated with a desalination plant may be minimized by appropriate actions and planning. Such measures must be tailored to the type and size of the desalination plant and the hydrogeological conditions present at the discharge area. We have also illustrated how the behavior of these brine discharges can be significantly modified by previous dilution of the effluent. We also recommend strict environmental monitoring to understand the behavior of this type of discharge with the aim of diminishing any associated impact.

\section{References}

[1] P.H. Gleick, Water in crisis: paths to sustainable water use, Ecol. Appl., 8 (1998) 571-579.

[2] M. Schiffler, Perspectives and challenges for desalination in the $21^{\text {st }}$ century, Desalination, 165 (2004) 1-9.

[3] J.A. Medina San Juan, La desalación en España. Situación actual y previsiones. Conferencia Internacional: El Plan Hidrológico Nacional y la Gestión Sostenible del Agua. Aspectos medioambientales, reutilización y desalación, Zaragoza, 2001.

[4] S. Lattermann and T. Höpner, Environmental impact and impact assessment of seawater desalination, Desalination, 220 (2008) 115.

[5] G.L. Meerganz von Medeazza, Direct and socially-induced environmental impacts of desalination, Desalination, 185 (2005) 57-70.

[6] A.J.Morton, I.K. Callister and N.M. Wade, Environmental impacts of seawater distillation and reverse osmosis processes, Desalination, 108 (1996) 1-10.

[7] R. Einav, K. Harussi and D. Perry, The footprint of the desalination processes on the environment, Desalination, 152 (2002) 141-154.

[8] A. Purnama, H.H. Al-Barwani and M. Al-Lawatia, Modeling dispersion of brine waste discharges from a coastal desalination plant, Desalination, 155 (2003) 41-47.

[9] C. Fritzmann, J. Löwenberg, T. Wintgens and T. Melin, State-ofthe-art of reverse osmosis desalination, Desalination, 216 (2007) $1-76$.

[10] M. Fariñas Iglesias, Ósmosis Inversa. Fundamentos, tecnología y aplicaciones, McGraw Hill/Interamericana de España, Aravaca, 1999.

[11] T. Höpner and J. Windelberg, Elements of environmental impact studies on coastal desalination plants, Desalination, 108 (1996) $11-18$.

[12] S. Lattemann and T. Höpner, Seawater desalination. Impacts of brine and chemical discharges on the marine environment, Desalination Publications, L'Aquila, 2003.

[13] P. Glueckstern and M. Priel, Optimized brackish water desalination plants with minimum impact on the environment, Desalination, 108 (1996) 19-26.

[14] D. Squire, J. Murrer, P. Holden and C. Fitzpatrick, Disposal of reverse osmosis membrane concentrate, Desalination, 108 (1996) 143-147.

[15] M. Ahmed, W.H. Shayya, D. Hoey, A. Mahendran, R. Morris and J. Al-Handaly, Use of evaporation ponds for brine disposal in desalination plants, Desalination, 130 (2000) 155-168.

[16] M. Ahmed, W.H. Shayya, D. Hoey and J. Al-Handaly, Brine disposal from reverse osmosis desalination plants in Oman and the United Arab Emirates, Desalination, 133 (2001) 135-147.

[17] M. Ahmed, A. Arakel, D. Hoey, M.R. Thumarukudy, M.F.A. Goosen, M. Al-Haddabi and A. Al-Belushi, Feasibility of salt 
production from inland $\mathrm{RO}$ desalination plant reject brine: a case study. Desalination, 158 (2003) 109-117.

[18] Y. Fernández-Torquemada, J.M. González-Correa and J.L. Sánchez-Lizaso, Preliminary results of the monitoring of the brine discharge produced by the SWRO desalination plant of Alicante (SE Spain). Desalination, 182 (2005) 395-402.

[19] J.V. Del Bene, G. Jirka and J. Largier, Ocean brine disposal, Desalination, 97 (1994) 365-372.

[20] R. Einav and F. Lokiec, Environmental aspects of a desalination plant in Ashkelon, Desalination, 156 (2003) 79-85.

[21] J.L. Pérez Talavera and J.J. Quesada Ruiz, Identification of the mixing processes in brine discharges carried out in Barranco del Toro Beach, south of Gran Canaria (Canary Islands), Desalination, 139 (2001) 277-286.

[22] N. Raventos, E. Macpherson and A. García-Rubiés, Effect of brine discharge from a desalination plant on macrobenthic communities in the NW Mediterranean, Mar. Environ. Res., 62 (2006) 1-14.

[23] R.L. Doneker and G.H. Jirka, CORMIX-GI systems for mixing zone analysis of brine wastewater disposal, Desalination, 139 (2001) 263-274

[24] K. Johnston, J.M. Ver Hoef, K. Krivoruchko and N. Lucas, ArcGIS 9. Using ArcGIS Geostatistical Analyst, ESRI, 2001. 